\title{
Nonlinear Modeling of Compression System and Stability with Recirculation
}

\author{
Aly El-Zahaby ' ${ }^{1}$ El-Shenawy Abd-Elhameed ${ }_{3}^{2}$ Zakarya Zyada ${ }^{3}$, Khaled Sad Eldin ${ }^{4}$ \\ and Mohamed Salem ${ }^{5}$
}

1,2,3,4 Mechanical Power Engineering Department, Tanta University, Egypt

5 Mechanical Engineer., Gasco Company, Egypt

(Tel : +20-10-517-1393; E-mail: m_salem1969@yahoo.con )

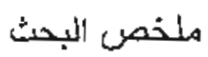

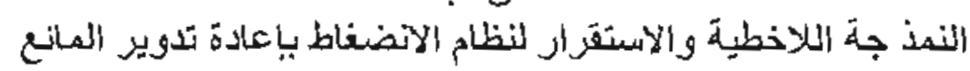

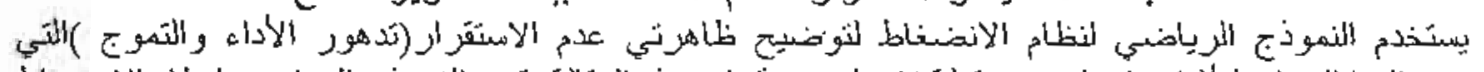

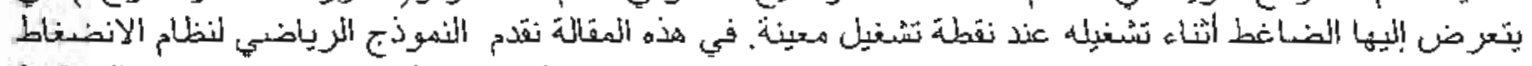

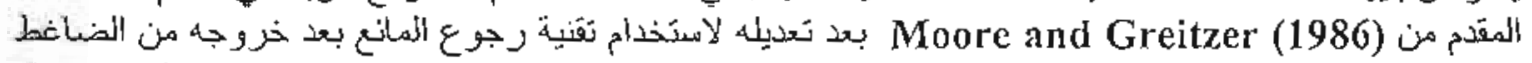

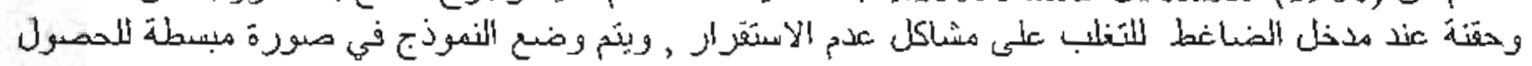

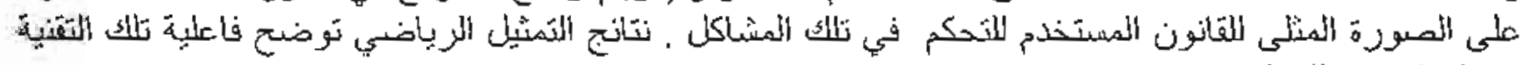

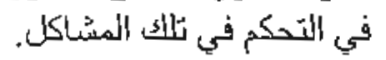

\begin{abstract}
The model of compressjon systen is used for capluring the dynamics of rotating stall and surge. In this paper, we introduce the modeling formulations of compression system after modifying the original work proposed by Moore and Greitzer (1986). Recirculation technique is used to eliminate the instabilities of compression system, where bled air from downstream compressor via bleed valves is re-circulated to injectors upstream of compressor inlet. The form of the modeling takes the four-state low order model which applied to design the nonlinear controller. The compressor works in stable regime by using recirculation techrique. Lyapunov Control Function (LCF) is used to produce optimal control to stabilize the compressor operation by using recirculation technique, whereas simulation results show that it is a good technique. By using recirculation technique bleed valves requirements are reduced.
\end{abstract}

Keywords: Compression system, Compression systen modeling with re-circulation, Surge control.

\section{Introduction}

Compressors are used, for example, as part of a gas a turbine for jel and marine propulsion or power generation, in superchargers and lurbochargers for internal combustion engincs, and in a vide variciy of industrial processes. Rotating stal) and surgc arc (wo aerodyumic instabilitics in turbo compressors. It is clear that both phenomena can affect cach other which give the simple fact that they occur in the same operaling region of lurbo-compressor. More specifically, surge can be regarded as the zeroth order eigenmode of the complete compression system while rolating stall is associated will higher order spatial modes inside the compressor [1]. The compression syslem model is used for capturing the dymamics of rotating stall and surge. Moore-Greitzer model [2] combincd the partial differential equation (PDE) describing the flows rield upstream of the rolor face and an ordinary differential equation (ODE) describing the ovcrall pressure rise dclivered by the compressor. The most conmon form of this model is a reduction of the PDE description to three coupled ODEs, lie reducion is accomplished by assuming a Fourier series for the solution of the PDE and llen truncating the scries at a single mode. Modeling and active control of rotating stall and surge has been investigated by a number of researchers. Day [3] usced the injection valves to damp out the stall cell after it las cmerged. This gave an increase in stall margin of about six percent. In the case of surge, it was shown that this instability is preceded by a brief period of rotating stall, and by using the air injection scheme to climinate the stall, and surge is also suppressed. The original Moore-Greitzer model [2] is developed by Belmiken [4], and Yeung [5] to include air injection 


\section{67 Aly El-Zahaby, El-Shenawy Abd-Elhameed, Zakarya Zyada,}

Khaled Sad Eldin and Mohamed Silem

putting the nonlinoar terms in their models. Injection cill influence the averall behavior of the compressor in lwo ways. The first is simply the additional momentum added by the jets which inereases the tolal pressure at rotor inlet. Tho second effect is a change in compressor performance which increases the pressure tise across the stage [6]. Implementing air injection is difficult bccause an independent source of comprossed air is required. In the oller side, Bleed valves present in moderis compressors and no air supply requited. Fonlaine et al. (7) used Bernoull['s equation, Moore's model [8], and Moore-Greitzer model [2] proposed the model of compression sysiem witl bleed valves at inter- slage of. an axial mullistage compressor using Gaierkin approximalion. Yeung [5] used conlinwous atr injection which serves to reduce the requirement of a bleed valves used for suppressing the rotaling slall. Niazi [9] uscd self-recircutation casing trealment 10 alleviate the stalt pbenomenon, and extend the stable operating range by delaying the initiation of surge. In this paper wo ase recitculation technique for the following reasons: the first is that source of air injection doesrit depend on external source, secondly, instcad of loosing the bled air, which is used in air injection, the third is that to keep the environment from pollution in case of usitug lhe compressor in pressurizing naturn gas, and the fourth reason is that air injeclion doesn't need auxiliary system and conseguently it needs low cost.

\section{Model witb reclrculation}

\subsection{Moore - Grcitzer model}

The basic compression system in Fig (1) consists of inlet duct, islet guide van, compressor, outlet duct, plenum, and throule valve. From assumptions of Moorc and Greitzer (1986) and applying Bernouli's equation, the lotal-to-static pressure rise upstream of the compressor can be written as:

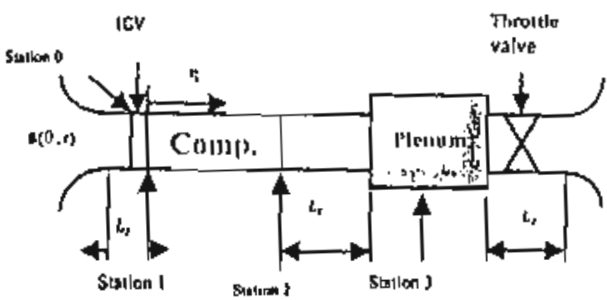

Figure (1): Scheme of comprcssion system for modeling.

$$
\begin{aligned}
\frac{P_{1}-P_{T}}{\rho u^{2}} & =\frac{-\phi^{2}}{2}-1, \frac{d \Phi}{d \zeta}-\frac{\partial \delta \phi}{\partial \zeta} . \\
\phi & =\phi+50 .
\end{aligned}
$$

$\zeta=\mathrm{tU} / \mathrm{R}$.

Where $\mathrm{P}_{\mathrm{P}}$ is the static pressure at station ( i ) where $j=\rfloor, 2, \ldots, P_{T}$ is the total prossure at ambient condition, $\Phi$ is the non-dimensionsl mean axial velocity, $\beta$, is the density,$\delta \emptyset$ is the non-dimensional axial velocily perturbation, $\phi=\frac{C_{X}}{u}$ is the non-dimensional local axial velocily, $\zeta$ is the non-dimensional time, $U$ is the Wheel speed at mean diameter, $R$ is the mean rolor radius, tIs the time, $C_{x}$ ts the iocal axial valocity, and $l_{1}=L_{1} / R$ is the tion-dimensional length of inlet duct.

\subsection{J Campressor}

The compressor is modeled as a semi-actuator disc such as:

$$
\begin{aligned}
& \frac{P_{2}-P_{T}}{\rho u^{2}}=F(\phi)-\lambda \frac{\partial \phi}{\partial \theta}-\mu \frac{\partial \phi}{\partial \zeta} . \\
& \Psi_{C}(\theta)=F(\phi)-\frac{\phi^{2}}{2} .
\end{aligned}
$$

where $F(\phi)$ is the nonlineas pressure rise map for the compressor as a function of the axial now, $\theta$ is the circumferential angle, $\mu$ is the fluid inertin parameter, $\lambda$ is the rotor inertia parameter.

Downstrean dynamics of compressor is given as:-

$$
\frac{P_{3}-P_{2}}{\rho u^{2}}=-I_{E} \frac{d \Phi}{d \zeta}-(m-1) \frac{\partial \delta \phi}{\partial \zeta} \text {. }
$$

where $I_{E}=L_{E} / R$ is the non-dimensional length of exit duct, $m$ is compressor - duct flow parameler, $m=2$ (for long enough cxil duct), and $\mathrm{n}=1$ (for a very shorl one). By defining:

$\psi=\frac{P_{3}-P_{T}}{\rho u^{2}}$.

where $\Psi$ is plenum pressuer tise coefficlent.

Fron the upstream, compressor and downstream dynamic the following PDE is oblained:

$$
\begin{gathered}
\psi=\psi_{c}(d x+\delta \theta)-1_{c} \frac{d \phi}{d \zeta}-\lambda \frac{\partial \delta \phi}{\partial \theta}-\mu \frac{\partial \sigma \phi}{\partial \zeta} \\
-m \frac{\partial \sigma \phi}{\partial \zeta} .
\end{gathered}
$$

$I_{c}=I_{E}+I_{i}+\mu$.

where $l_{1} l_{E}, l_{T}, l_{c}$ are length of entrance, exit, throllie, and effeclive length of selup divided by wheel radius respectively.

Cloosing:-

$\delta \theta=A_{1}(\zeta) \sin (\theta-\zeta)$.

where $A_{1}$ is the amplitude function of first-lamonic angular disturbance and computing the annulus-average, sinc and cosine moments of equation (8) gives rise to a scl of equations describing the time evolution of $\Phi$, $\int=A_{1}{ }^{2}$ and $r$ these cquations are as follows

$$
\begin{aligned}
& \frac{d \Phi}{d \tau}=\frac{1}{I_{c}}\left[\Psi_{c}(\Phi)-\Psi^{\prime}+\frac{j}{4} \frac{\partial^{2} \Psi_{c}(\Phi)}{\partial \Phi^{2}}\right] . \\
& \left.\frac{d]}{d t}=\frac{2}{m+\mu}\right]\left\{\frac{\partial \Psi_{c}(\Phi)}{\partial \Phi}+\frac{i}{\theta} \frac{\partial^{2} \Psi_{c}(\Phi)}{\partial \Phi^{2}}\right] . \\
& \frac{d r}{d t}=\lambda(m+\mu) .
\end{aligned}
$$

which describe that the stall of compressor rotor is at a constant speed.

\subsubsection{Plenum Mass Dalance}

Balancing the mass going Into, leaving and being stored In the plenum gives:

$$
\begin{aligned}
& \frac{d \Psi}{d \zeta}=\frac{1}{\left.4\right|_{c} b^{2}}(\phi-\gamma \sqrt{\Psi}), \\
& \mathrm{B}=\frac{\mathrm{v}}{2 a_{s}} \sqrt{\frac{V_{p}}{A_{c} L c}} .
\end{aligned}
$$

where $B$ denotes the Greitzer parameter, $a_{S}$ is the speed of sound, $V_{p}$ is the volume of the plenum, $A_{c}$ is the 
compreasor dugt area, $L g=l_{f} R$ fo lho ochiblynumica fength of the system, and y the throule choticient.

\subsubsection{T'írultle valvo}

The throttle charscteristis la laken ag:

$\Phi_{\text {. }} \circ \gamma \sqrt{\mathrm{y}}$.

Where $\phi_{\text {p }}$ is the thratkle flow coeffclent.

\subsubsection{Charactertatlics}

The compresslon system characteristics are taken form [2]. The usun 3at order polynomial steady compressor is employed:

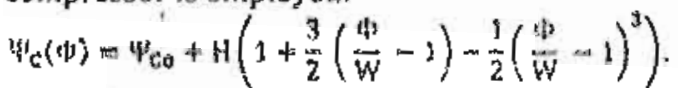

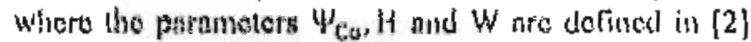
Tho compressor characteristics can alyo bo plollod dis in fanily of curves. One line for each rolational speed, with the surge line passing llurotgin tho iocal amaxintum of tho constant speed lines. Using the nondimentionalizing entoloyed horo and when the compressor is in folaling sla!l the characteristics is glven by,

$\left.\psi_{3}(\Phi)=\psi_{c_{0}}+1\right\}\left(1-\frac{3}{2}\left(\frac{w}{W}-1\right)+\frac{5}{2}\left(\frac{b}{W}-1\right)^{3}\right)$.

\section{1.5 Fitat form of the moul}

Colloating the oquations (11), (12), sind (14), the following 3-slate system is uscd as a low onder modol for siall nind surgen.

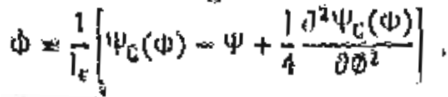

$$
\begin{aligned}
& \phi=\frac{1}{\|\|_{c} B^{i}}\left(\phi-\phi_{f}\right) \\
& 1=\frac{2}{4+11} \mid \frac{0+p_{c}(\phi)}{3 b} \\
& \left.+\frac{j}{0} \frac{\theta^{3} \varphi_{c}(\phi)}{\partial \omega^{t}}\right\} \text {. }
\end{aligned}
$$

\section{2,2 Manto - Greltzer Motel witi Air injectlon}

There sic two primary effects cnused by nidiug air injecton to comprosston system [4], hio first oue is a shith in the sleady-stnto comprestor pertomance oharhotorislice and the second is nomentum neddition offers. Tho pliysical effert for udding air injection inlo Ho model as a dilin to tho stendy-stalo compressor chatacteristion bosed on axporimental resulls is presented by D'Andrea ef al., [10], where air injection actualors substontially shifted tho compressor perforthance dharacleristios. The letan which was proposed by Oyaling of al, [II] is that al nctuator could affect the pressure fiso delivered by tho compressot. On the Coltouls the shin is used primarily io model the

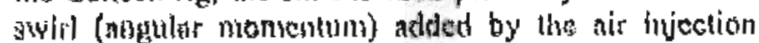
aetuators. In addition to the swirl componont, air injection also adds mass mol momentum to the wulnpressor inlei. In Fig. (2), the full order model enn be appoximatod by a sel of ardinnty dilTerential outations using Galurkin's method.

The differeutial oquntions describing tho total and slatic pressure based on a potential now solution in inlet duct may be given as follows;

$$
\begin{aligned}
& \left.\left[\left(\frac{2}{n}+\mu\right) \frac{\partial}{\partial \zeta}+\lambda \frac{\partial}{\partial \theta}\right)\right]\left(6 \phi_{1}+\frac{\delta L_{1}}{L_{1}} \Psi_{1}\right) \\
& =\Psi_{\text {c(afrecliva })}-\psi-i_{\mathrm{C}} \frac{\mathrm{d} \Phi}{\mathrm{d} \mathrm{l}} \text {. } \\
& \Psi_{c(\text { teflactivc) }}=\Psi_{c}\left(\Phi+6 \phi_{1}+\frac{\delta L_{1}}{L_{a}} \phi_{J}\right)+\left(\Phi_{1}-\Phi+\right. \\
& \text { 80, }) \frac{b L_{1}}{L_{1}} \Phi_{j}-\frac{1}{2}\left(\frac{k L_{2}}{L_{1}} \dot{\Phi}_{1}\right)^{2} \\
& \left.6 a_{1}=0-1\right)=\sum_{n=1}^{\infty} b_{n} \cos (n \theta)+b_{n} \sin (n \theta) \text {. }
\end{aligned}
$$

where $6 \phi_{1}$ denoles tho asynmelsic conponent of $\theta_{n} a_{n}$ and $b_{n}$ are the fourler cochicients of $\phi$.

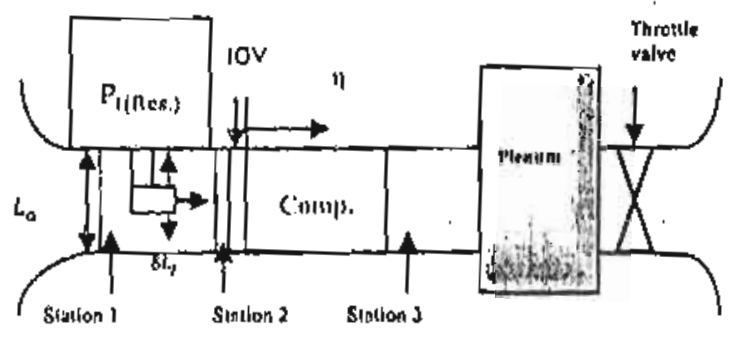

Figure (2): Sclremo of compression syslem wilh air injector

The solution is first writlen as tho linear combinelion of once more assunned basis functions and substituted into the partial difforential oquation. The resulting residual crror $(\epsilon)$ becomes:

$$
\begin{gathered}
\epsilon=\operatorname{a} \cos \theta+\dot{b} \sin \theta-\lambda(a \cos \theta-b \sin \theta) \\
+\psi_{e(e \text { Tectlve) }} .
\end{gathered}
$$

This lesidunl enor is minimized by making it arlhogonal to eacl of the nssumed basis functions. For the rotating stall problem, lhe how field's spatinl Fourier coellieicnts are conveniont basis functions for the projection consider the first spatial harmonic ( $n=1$ ). The residual is mitrituizod by making it orlhogonal to anch basis nunction $\cos (\theta)$, and $\sin (\theta)$.

The Galerkin approxinntion is caloulaled using tho wolght funotions

$h_{1}=1, h_{2}=\sin \theta_{1} h_{3}=\cos \theta$.

$\left\langle\varepsilon \mid h_{1}\right\rangle=\frac{1}{2 \pi}\left[\int_{0}^{2 \pi}\left[\epsilon h_{1}\right] d \theta\right]$.

Calculating the nomonts

$M_{t}=\left\langle\mathrm{e} \mid h_{i}\right\rangle=0 \quad$ far $l=1,2,3$

The foul-stnte Onlorkin model can bo syritten ns

$$
\begin{aligned}
& \phi=\frac{1}{2 \pi L_{5}}\left[\int_{0}^{3 n}\left[\Psi_{\text {a(OnEstlve) }}-\psi\right\rangle d \theta\right\} \text {. } \\
& \psi=\frac{1}{4 i_{C} B^{2}}\left(\Phi+\frac{\delta L_{i}}{L_{d}} \phi_{1}-\phi_{T}\right) .
\end{aligned}
$$


M. 69 Aly El-Zahaby, El-Shenawy Abd-Elhanced, Zakarya Zyada,

Khaled Sad Eidin and Mohamed Salem

$$
\begin{aligned}
& \vec{a}=\frac{1}{m+\mu}\left[-\lambda b+\frac{1}{\pi} \int_{0}^{2 \pi}\left[\Psi_{c(c)[c, i v e)} \cos 0 \mathrm{~d} \theta\right]\right] \text {. } \\
& \dot{b}=\frac{1}{m+\mu}\left[\lambda a+\frac{1}{\pi} \int_{0}^{2 \pi}\left[\psi_{\text {ceflective) }} \sin \theta d \theta\right]\right] \text {. }
\end{aligned}
$$

After integration, the modeling of compression sysicm, with air injection is developed in the following form:-

$$
\begin{aligned}
& b=\frac{1}{i_{c}}\left[\left[\Psi_{c}(d)+\frac{1}{4} \psi_{c}^{\prime}(d)\left(a^{z}+b^{2}\right)-y^{2}\right]+\left[y_{c} c(d)\right.\right. \\
& +\frac{1}{4}{ }^{\prime \prime} \psi_{c}^{\prime \prime r}(d)\left(a^{2}+b^{2}\right)+w_{i} \\
& \left.-\infty] \frac{\delta \mathrm{L}_{\mathrm{j}}}{\mathrm{L}_{\mathrm{a}}} \mathrm{\omega}_{\mathrm{h}}\right] \\
& \dot{\Psi}^{\prime}=\frac{1}{4 I_{\mathrm{c}} \mathrm{B}^{2}}\left(\Phi+\frac{\delta \mathrm{L}_{l}}{\mathrm{~L}_{\mathrm{b}}} \Phi_{\mathrm{j}}-\Phi_{\mathrm{T}}\right) \text {. } \\
& \dot{a}=\frac{1}{m+\mu}\left[-\lambda b+\left[\Psi_{c}(\Phi)+\frac{1}{8} \Psi_{c}^{\prime \prime \prime}(\Phi)\left(a^{2}+b^{2}\right)\right] a\right. \\
& \left.+\frac{\delta \mathrm{L}_{i}}{\mathrm{~L}_{\mathrm{a}}} \phi_{\mathrm{l}} \mathrm{a}\left(\Psi_{\mathrm{c}}{ }_{\mathrm{c}}(\phi)+1\right)\right] \text {. } \\
& \dot{b}=\frac{1}{m+\mu}\left[\lambda_{a}+\left[\Psi_{c}(\Phi)+\frac{1}{b} \Psi_{c}^{\prime \prime \prime \prime}(\Phi)\left(a^{2}+b^{2}\right)\right] b\right. \\
& \left.+\frac{\delta \mathrm{L}_{1}}{\mathrm{~L}_{\mathrm{a}}} \Phi_{\mathrm{i}} \mathrm{b}\left(\psi_{\mathrm{c}}(\mathrm{Q})+1\right)\right] \text {. }
\end{aligned}
$$

where $\Psi_{c}^{\prime}(\Phi), \Psi_{c}^{\prime}(\Phi), \Psi_{c}^{\prime \prime \prime}$ (Ф)are the first, second , and third derivative of $\psi_{c}(\mathrm{~d})$ with respect to $(\mathrm{w}$

\subsection{Moore-Greltzer Mode[ willu bleed va]ve}

Full order model of compression system witı blod valve according to Fontaine [7] is given as follows

$$
\begin{aligned}
& \Phi=\frac{1}{l_{c}}\left[\Psi_{c}(\Phi)+\frac{1}{4} \Psi_{c}(\Phi)\left(a^{2}+b^{2}\right)+\phi \Phi_{\mathrm{b}}-\Psi\right. \\
& \left.+\frac{1}{2}\left(a C_{a}+b c_{b}\right)\right] \\
& \dot{\psi}=\frac{1}{4 I_{c} B^{2}}\left(\Phi-\Phi_{b}-\Phi_{r}\right) \text {. } \\
& a=\frac{1}{m+\mu}\left[-\lambda b+\left(\psi_{c}^{j}(d)+\frac{1}{8} \psi_{c}^{\prime \prime \prime}(\omega)\left(a^{2}+b^{2}\right)+c b_{b}\right) a\right. \\
& \left.+\Phi C_{a}\right] \text {. } \\
& \dot{b}=\frac{1}{m+\mu} \mid \lambda a+\left(\psi_{c}^{i}(\Phi)+\frac{1}{B} \mu_{c}^{\prime \prime \prime}(\Phi)\left(a^{2}+b^{2}\right)+D_{b}\right) b \\
& \left.+\phi C_{b}\right] \text {. }
\end{aligned}
$$

\subsection{Modeling of recirculation}

As indicated in Fig. (3), air is re-circulated from the compressor downstream to injector at upstream of compressor. In this case, we assume $\omega_{b}=\Phi_{j}$, $\frac{\delta L_{j}}{L_{a}}=1$, from section (2-2), and section (2-3), lhe low order model for air recirculation is developed in the form :

$$
\begin{aligned}
\phi=\frac{1}{I_{c}}\left[\Psi_{c}(\Phi)+\frac{1}{4}\right. & \Psi_{c}^{2}(\Phi)\left(a^{2}+b^{2}\right)-\Psi+\left(\Psi_{c}(\Phi)\right. \\
& \left.+\frac{1}{4} \Psi_{c}^{n t}(\Phi)\left(a^{2}+b^{2}\right)+\Phi_{b}\right) \Phi_{b}+\frac{1}{2}\left(a C_{a}\right. \\
& \left.\left.+b C_{b}\right)\right],
\end{aligned}
$$

$$
\begin{aligned}
& \dot{\psi}=\frac{1}{1]_{C} B^{2}}\left(q-\Phi_{\tau}\right) \text {, } \\
& a=\frac{1}{m+\mu}\left[-\lambda b+\left(4{ }_{c}(d)\right.\right. \\
& +\frac{1}{8} \psi_{\mathrm{c}}^{\mathrm{nt}}(\Phi)\left(\mathrm{a}^{2}\right. \\
& \left.+b^{2}\right)+2 \Phi_{b}+\Phi_{b}\left(\Psi_{c}(\omega)\right) a \\
& \left.+\phi C_{a}\right] \text {. }
\end{aligned}
$$$$
b=\frac{1}{n+\mu}\left[\lambda a+(]_{c}(d)\right.
$$$$
+\frac{1}{8} \psi_{\mathrm{c}}^{t+t}(d)\left(\mathrm{a}^{2}\right.
$$$$
\left.+b^{2}\right)+2 w_{b}+\psi_{b}\left(w_{c}(\omega)\right) b
$$$$
\left.+\phi C_{b}\right] \text {. }
$$

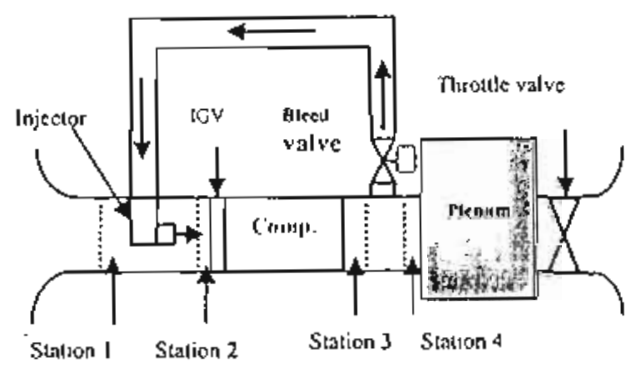

Figure (3): Scheme of compression system with recirculation

\subsubsection{Surge subsystem and stall subsystem}

Wo refer to equations (41)-(42) as the surge subsystem .In the surgc subsystern, the characteristic $\psi_{c}(D)$ is the locus of equilibrium values for the mass How parameter $\$$ and the pressure rise parameter $\psi$ '. A desired equilibriun is selccted by adjusting the throtle cocficient $\gamma$. Decreasing the value of $\gamma$ corresponds to closing the throttle valve, which decrcases the mass flow and increases the pressure rise. The cubic claracleristic $\Psi_{c}(\mathrm{D})$ in fig. (4) lias one local maxinum (peak). To the right of the peak, the equilibrium is locally stable withou: feedback. To the ieft of the peak, the cquilibrium is unstable. The surge subsystem describes the fluid in plenum as a nonlinear spring. Under certain condilions, compressor enters a surge limit cycle and undergoes large oscillations in $\Phi$ and $\Psi$ that often include negative values of $\Phi$. In the stall subsystem equations (43)-(44), to the left of the peak, the slope of lle characteristic is posilive. The resulting instability is known as "rotating stall" involves oscillations in a, and b which are damaging to the engine and reduce the pressure tise across the compressor.

\section{Stability and control design}

\subsection{Design objective}

When the mass flow rate of the compressor is reduced duc to closing the throltic valve. 1his causes two dlow instabilitics (rolating stall and surge). Without an cffective feedback controller, the effect of these instabilities may drive the compressor into a region fron 
which it does not return to a desired stcauly-state operation. The main task of a feedback controller is 10 enlarge the region of the asymplotically stable equilibrium which represents the desired stcady-statc compressor operation. Our desired cquilibrium is the highest pressure rise at the peak of the characteristic. We design lincar and nonlineate control laws to assess the controlier's ability to maintain fhis equilibrium. By using these controllers we can move the stall-surge inception point to lower value of (D), linereby increasing the operating range of the compressor and consequently optinizing sleady-statc perfornance.

\subsection{Lympunov stability analysis}

This section illustrates the Lyapunov stabilisy proof for the arbitrary order Moorc - Greitzer model and shows how controllers can be derival using this theory. Consider the state crror vector $\mathrm{e}=\mathrm{x}-\mathrm{x}_{e \mathrm{q}}$ where $x_{e q}$ is the desired equilibrium point. A simple candidatc Lyapunov function (V) in the absence of actuator is stated. This function measures the tolal perturbation kinctic and potential encrgy slored in the compression system. When the actualor is included, this Lyapunov function measures the perturbation encrgy in an "equivalent compressor" that accounts for the effects of actuator on the compressor state. Thic perlurbation energy is guarantect to go to zera if the perlurbation power, $\vec{v}$ is negalive dolinitc.

\subsection{Basic controllibility}

Let us consider the issue of contrullability. It fintitu dimensional control theory, a systcm is said to bc controllable i[ for cucry lwo poinls $x_{0}, x_{t} \in x$ and cvery two real numbers $t_{0}<t_{1}$, there cxisis a control function (u) such that the unique solution of the equalion:

$\dot{\mathrm{x}}=\mathrm{f}(\mathrm{x}, \mathrm{v}), \mathrm{x}\left(\mathrm{t}_{\mathrm{n}}\right)=x_{0}$.

Satisfies $x\left(t_{1}\right)=x_{1}$

\subsection{Lluenrization}

Therc are many ways to design control laws to achieve $\dot{V}<0$ is the vicinity of the equilibrium point to enlarge the domain of altraction, and to make $\dot{V}$ more negative to incrcase robustness to modeling crrors. Ouc way to impose a negative defimite $\vec{V}$ is to cancel the dynamics introduced by the compressor characteristic and replace them with some desired linear dynamics. The form of linear system takes the following form:

$\mathrm{x}=\mathrm{A} \mathrm{x}+\mathrm{B}$.

Where $A$, and $B$ are the matrices of the linearization of equations (4l-44) appear in a decoupled block diagonal structure,

$A=\left[\begin{array}{cc}A_{1} & 0 \\ 0 & A_{2}\end{array}\right] \cdot B=\left[\begin{array}{cc}B_{1} & 0 \\ 0 & B_{2}\end{array}\right]$

Tluis allows for decomposition into two subsystems.

axisyunctric control variable $\Phi_{b}$ controls $\omega$, and $\psi$ in the linearized surge subsysten where

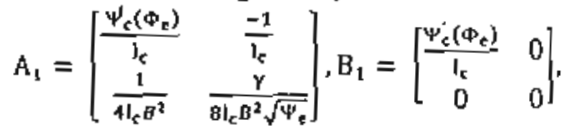

Surge subsystem alone is controllable at all s inilibrium noinis un the compressor characteristic.

The stall subsystem by linearization:

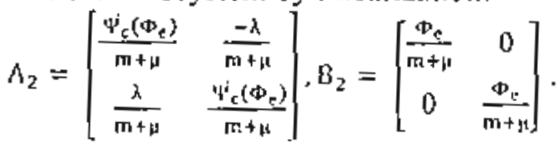

Is controlled by $C_{a}$, and $C_{b}$, see ref. [7].

\subsection{Surge control design}

Compressor's steady- state performance is determincd by the operaling point on the characteristic $\Psi_{c}(\Phi)$. The highest pressure rise $\psi$, and hence, the best steady- state performance is achieved at the pcak of $\Psi_{c}(\phi)$. However, tho pak is nol a slable equilibriun of the unconlrolled system. Our design objeclive is to stabilize the peak and provide as large a region of attraction as possible.

\subsubsection{Linear control Design: LQR Control}

The control that minimizes the cost function $J=\int_{0}^{\infty}\left(x^{\top} Q x+u^{\top} R u\right) d t$ is given by $L Q R$ design in ref. [12].

$u=-R^{-1} B_{1}{ }^{\top} P_{1}^{\top} \tilde{X}$.

Where $P_{1}$ is the positive definitc solution of the Algebraic Ricatti Equation (ARE)

$A_{1}{ }^{\top} P_{1}+P_{1} A_{1}-P_{1} B_{1} R^{-1} B_{1}{ }^{\top} P_{1}+Q 1=0$.

The solution $P l$ exisls because the pair $[A \mid B I]$ is controllable for all operating points on the compressor chatacteristict $\psi_{c}(\$)$. Thus, the LQR design results in loc:al asympolic stability of the surge subsystem.

\subsubsection{Nontincar control design}

Many nonlinear control designs arc introducco in ref. [13], and [14]. Bccause of simplicity of a nonlincar controller design, similar to [7], it is applied to produce the current surge control wilh recirculation which take the form

$\dot{\mathrm{x}}_{1}=f_{1}+g_{1} \omega_{\mathrm{b}}$.

Whore

$f_{1}=\left[\frac{1}{1_{c}}\left(\Psi_{c}(d)-w\right) \quad \frac{1}{w_{c} J^{2}}\left(\omega-\omega_{T}\right)\right]$.

$g_{l}{ }^{\mathrm{T}}=\left[\begin{array}{ll}\frac{\psi_{c}(\psi)}{l_{c}} & 0\end{array}\right], \quad \dot{x}_{1}^{\top}=\left[\begin{array}{ll}\dot{\phi} & \dot{\psi}\end{array}\right]$

We now design a simple nonlinear controlfer to increase the negativity of $\dot{v}(x)$ for the same Lyapunov function $V(x)=x^{T} P_{1} x$. The region $V(x)<0$ is increased by selection of the control law [7] as follows:

$u=-R^{-1} g_{1}{ }^{\top} P_{1}{ }^{\top} \tilde{x}_{1}$.

4. Simulation results

\subsection{Surge modiel}

In this section it, is illustrated that the developed model is capable of simulating surge. Results are presented from simulations of the compressor system when diven into surge by a drop in mass flow at $\gamma=0.5$ which move the throttle characieristic to the lcft of the top of stcady state characlerislic as indicated in figure (4). Simulation paramelers are shown in table (1) which are taken from [15], The compressor under this condition undergoes deep surgc with oscillations in mass flow, and pressurc rise, as shown in figure (5), where the 
flucluation of $(4, \Psi)$ will respect to lime, antel the phinse pion $\left(\Phi, \Psi^{\prime}\right)$, where surge cycic exist. The surge las oscillation will a period $\zeta \approx 500$. This is corresponding to surge frequency of about $4.4 \mathrm{~Hz}$

\section{2 surge coutrol}

By using the norlinear control law the bleeding air is re-circulated to be injected at compressor's upsircan. The compressor can operate in a stable mode cven lo llic left of the surge line. In ligure ( $G$ ) nass Mow drous as in the surge sinulation is introduced at $:=0.18 \mathrm{~s}$, a fler that the compressor remains stable. This figure exphins the stabilization of $(\Phi, \Psi)$ with respect to time and the pliase pian $(\Phi, \Psi)$ where the opcraling point converges to equilibrium yoint.

Table, (1) numerical values simulations

\begin{tabular}{|c|c|c|c|c|c|}
\hline Sym. & value & Sym. & value & Symi & Value \\
\hline $\mathrm{R}$ & $0.1 \mathrm{~m}$ & $\mathrm{i}_{\mathrm{c}}$ & 13.3 & $\Psi_{\mathrm{co}}$ & 0.3 \\
\hline $\mathrm{U}$ & 0.18 & $\mathrm{~B}$ & 1.8 & $\mathrm{U}$ & $215 \mathrm{m1} / \mathrm{s}$ \\
\hline $\mathrm{W}$ & 0.25 & $\mathrm{~W}$ & 0.25 & $\gamma$ & 0.5 \\
\hline
\end{tabular}

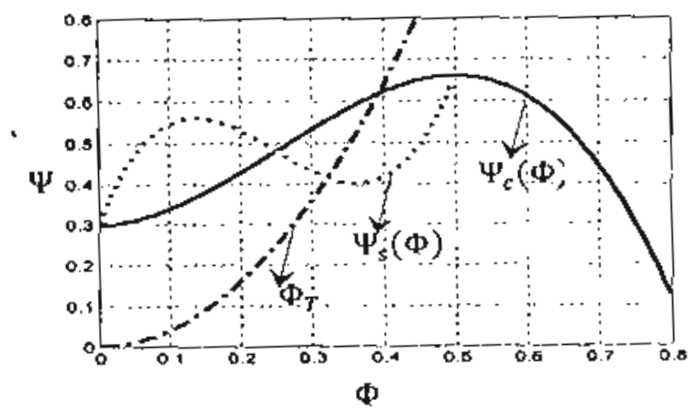

Figure (4): Conpression sysleın characicristic.
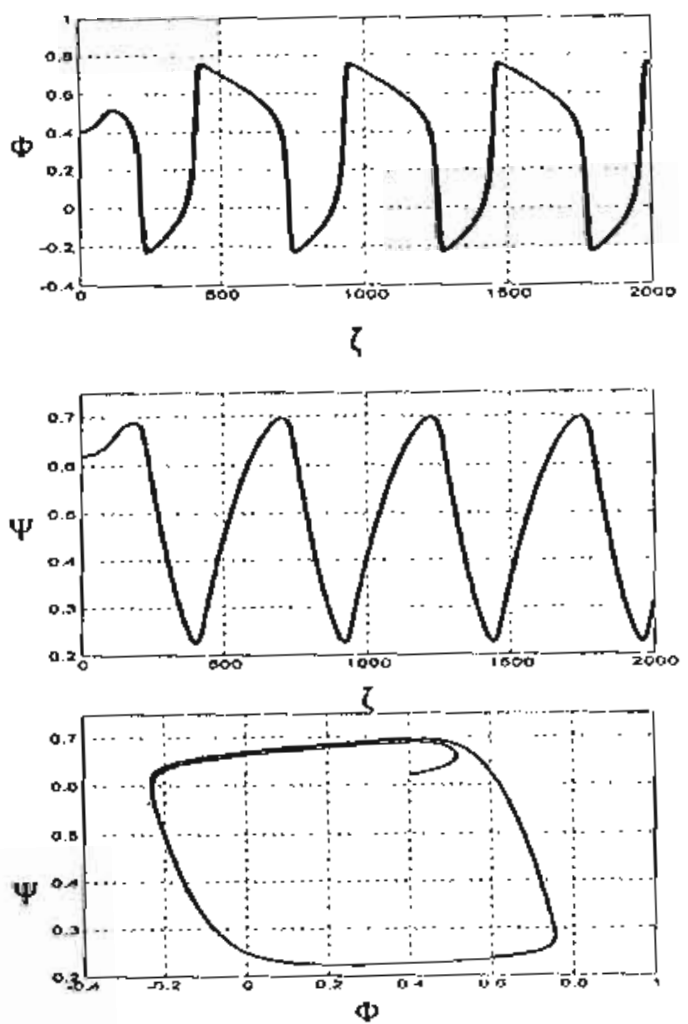

Figurc (5): Simulation of sub-surge system, at $B=1.8$.

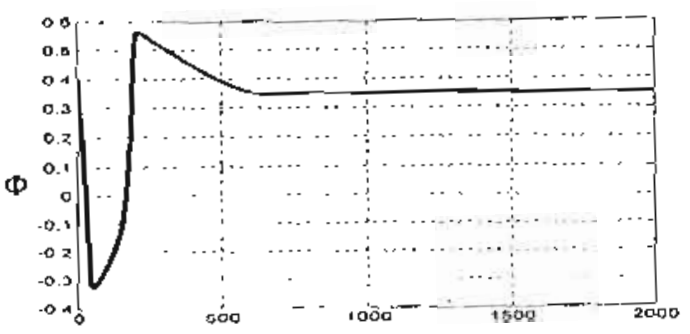

$\zeta$
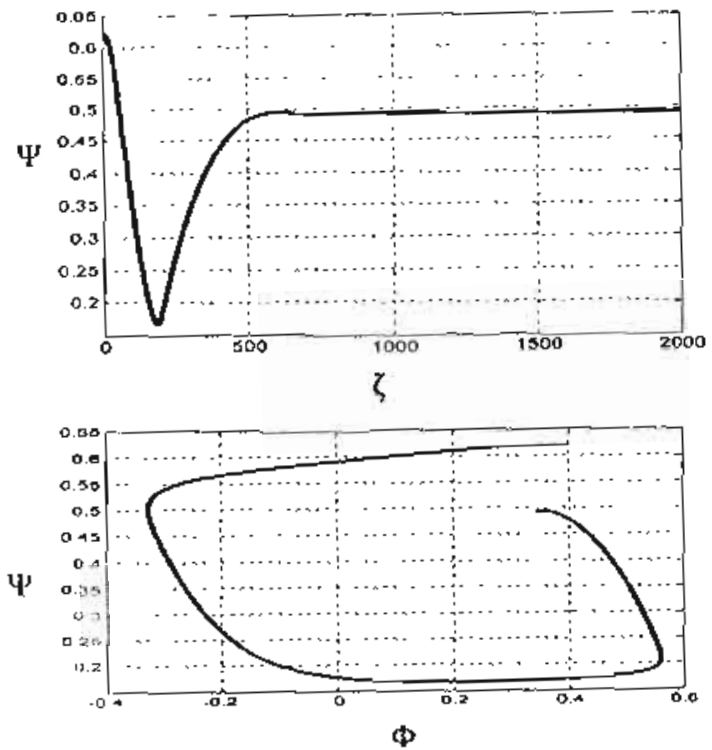

Figure (6): Stabilization of compressor using nonlinear control

\section{Conclusions and future work}

Moor-Greitzer compression system with recirculation tcchnique has becn developed. Lyapunov function is applied to introduce linear and nonlinear optimal control to stabilize the compressor when it undergoes surge. Simulation results show that recirculation tcclnique is powerlul for stabilizing the conpressor at higher Greitzer parameter (B), where the operatiıg point lics in the unslable regine. Future work includes: 1) use of Lyapunov function to introduce linear and nonlinear control design to stabilize the compressor when it undergoes a rotating stall, 2) investigate recirculation technique for stabilizing the compressor and validating the rcsults experimentally, 3) nodeling of higler harmonics in rotating stall, which includes more tcruns in the Fourier series of flow coefficient fluctuation applying re-circulation technique.

\section{Referelices}

[1] D Paduano, E. M. Greizer, and A. H. Epslein, "Compression systcm stability and active control", $A m$. Rev. Fluid Mechanics, 33, pp. 49i-517, 2001.

[2] F. K. Moore, and E. M. Greitzer " $A$ theory of post-stals Transients in axial compression systems, pari 1. 
Devciopnent of equations", Jorrat of Engineeritg for Gas Tuvines and Power. Vol. 108 , pl. 68-76, Jim. 1\%86.

[3] 1.J. Day, "Aclive suppression of rolitung stiall alid surge in axiah compressors". ASME, 40, Vol, 115, Jan. 1993.

i4) R. L. Belinken, "Nonlinear control and modeling of rotating siall in an axial compressor". ThD. Thesis. 1990.

[5] S. Ycung," Nonlincar comtrol of rotating stall and surge wilh axisymmelrie blecd valve and air injection", PhD Thesis, 1998.

[6] H. J. Weigl, "Active Stabilization of Rotating Stall and Surge in a Transonic Single Slage Axial Compressur". Pho. Theris, 1997.

[7] D.Fontaine, S.Lino, J. Paduane, and V. Kukutovic, "Norslincar control experimens on an axial how compressor", IEFE Thansacrions an Control symem. Techology, Vol, 12, No. 5 Scp. 2004.

[8] F. K. Moore. "A licory of retaling sall of muliskage axial compressors: part 1- sinall disturbances. "S. Fig. Gas Turbines Powe; Vol. 106, pp 313-320, $\wedge \mathrm{pr}$. 1984

[9] Niazi, I. Vishwas, N.S. Lakshmi, "Assessmenl of the Scl[-Recirculating Casing Treatment Concept to Axial Compressors", AIAA-0632, 2005.

[10] R. D'Nudrea, R. L. Belinken, and R. M. Murray. "Activo control of an axial flow compressor vin pulsed vir injection ", ASME Jounal of Twho-nluchincry, vol. 119. No. 4, pp. 742-752, 1997.

(ii) D.L. Gysing E.M. Grcilzer, "Dynamic control of ronaling stall inaxial compressors using Acromechanient feedback", ASME Joumal of Thrbo-machiner. Vol. 117. No. 3, pp. 307-319. 1995 .

[12] R. E. Kalman, "Whicn is a lincar conlrol sysicm oplimal?", J. Basic Eng., Vol. 86, pp. 51-60, Mat 1964.

[13] E. D. Sumag, " $A$ universal consinuction of artslcen's theorcm on monlinear stabilization", Syat. Control fent. Vol. 13, pp. 117-123, 1989.

[14] R. Sepulchre, M. Jankovic', alnl P', Kolkurovic', "Construclive Nonlincar Contrul", New Yarki: SpringerYerlog. 1997.

[15] J. T. Grovdh. "Modeling and control of surge and rotating stail in compreseors", PhD. Theris, 1998. 